\title{
VARIACIÓN DE LA REGIÓN RIBOSÓMICA NUCLEAR EN Crataegus L. DEL CENTRO Y SUR DE MÉXICO ${ }^{1}$
}

\author{
Carlos Alberto Núñez-Colín², Ernestina Valadez-Moctezuma ${ }^{3}$, Alejandro Facundo Barrientos-Priego ${ }^{3}$, \\ Fernando González-Andrés ${ }^{4}$, Raúl Nieto-Ángel
}

\section{RESUMEN}

Variación de la región ribosómica nuclear en $\mathrm{Cra}$ taegus L. del centro y sur de México. Este estudio fue realizado en la Universidad Autónoma Chapingo y concluido en octubre de 2008 y tuvo como objetivo determinar las relaciones genéticas entre especies de Crataegus del centro y sur de México. La variación en las secuencias de la región ribosómica nuclear fue baja en todas las accesiones de germoplasma de Crataegus mexicanos, y el filograma sólo mostró separación de las especies usadas como controles positivos, pero no mostró una clara separación de grupos de especies. Sin embargo, todas las accesiones tuvieron un mismo patrón de sustitución de nucleótidos y muy bajos valores en la distancia de composición de nucleótidos; por lo que las especies mexicanas de Crataegus mostraron alta relación genética, pero falta evidencia para concluir que son variantes de una misma especie taxonómica. $C$ nelsoni y $C$. stipulosa pueden ser una fuente de genes para $C$. mexicana porque ambas especies, originarias de Chiapas, tienen la más estrecha relación con esta especie, que es la que presenta las mejores características agronómicas.

Palabras clave: ITS-1, ITS-2 y 5.8S rDNA, secuenciación de ADN, Tejocote, Rosaceae Sub-tribu Pyrinae.

\begin{abstract}
Variation of the nuclear ribosomal region in Crataegus L. from central and southern Mexico. This study was conducted at the Universidad Autónoma de Chapingo and concluded in October 2008, to determine the genetic relationships among species of Crataegus from central and southern Mexico. The variation in the sequences of the nuclear ribosomal region was low in all accessions of germplasm of Mexican Crataegus, and the phylogram only showed separation of the species used as positive controls, but did not show a clear separation of groups of species. However, all accessions had the same pattern of nucleotide substitution and very low values of the distance of nucleotide composition; thus, Mexican Crataegus species have high genetic relationship among them, but there is a lack of evidence to conclude that they are variants of the same taxonomic species. C. nelsoni and C. stipulosa could be a source of genes for $C$. mexicana because both species, from Chiapas, have the closest relationship with this species, which has the best agronomic characteristics.
\end{abstract}

Key words: ITS-1, ITS-2 and 5.8S rDNA, DNA sequencing, Tejocote, Rosaceae Sub-tribe Pyrinae.

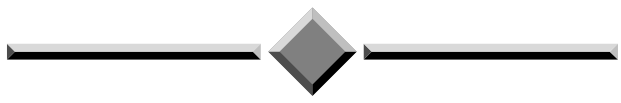

\footnotetext{
1 Recibido: 5 agosto, 2010. Aceptado: 16 de mayo, 2011. Parte de los resultados del proyecto número 53 de la Red de Frutales del Sistema Nacional de Recursos Fitogenéticos. SINAREFI, México.

2 Campo Experimental Bajío, Instituto Nacional de Investigaciones Forestales, Agrícolas y Pecuarias. Km. 6.5 Carretera Celaya - San Miguel de Allende. Apartado Postal 112. Celaya, 38010, Guanajuato, México. lit007a@gmail.com

3 Instituto de Horticultura, Departamento de Fitotecnia, Universidad Autónoma Chapingo Km. 38.5 Carretera México - Texcoco, Chapingo, 56230, Estado de México, México. Autor para correspondencia: nestty56@yahoo.com.mx

4 Departamento de Ingeniería y Ciencias Agrarias, E. S. T. Ingeniería Agraria, Universidad de León. Av. Portugal 41, León, 24071, Castilla y León, España.
} 


\section{INTRODUCCIÓN}

El género Crataegus pertenece a la familia Rosaceae subtribu Pyrinae (Campbell et al. 2007). Está constituido por aproximadamente 140 especies a nivel mundial divididas en cuarenta series, de las cuales dos terceras partes se encuentran en Norteamérica y el resto en Europa y Asia (Phipps et al. 2003).

Crataegus L. es el más grande y taxonómicamente complejo de los géneros de plantas arbóreas de Norteamérica (Phipps et al. 2003). La taxonomía de este género en México no es clara debido a que sólo se han propuesto dos tratados botánicos al respecto. El primero fue hecho a principios del siglo veinte por Eggleston (1909), y el más reciente, que sólo incluye el norte y algunas regiones del centro de México, fue propuesto por J. B. Phipps (1997). No existe una clasificación completa de este género en México, ya que falta colecta e identificación principalmente para los estados de Morelos, Guerrero, Veracruz, Oaxaca y Chiapas (Núñez-Colín 2008).

Se ha reportado que en el centro y sur de México fueron encontrados un complejo de especies relacionadas con C. mexicana DC (C. mexicana sensu lato), incluyendo especies pertenecientes a la serie Mexicanae (Loud.) Rehder (Phipps 1997), como lo son $C$. stipulosa (Kunth) Steud descrita por Eggleston con ese nombre) y C. nelsoni Eggl. (Phipps et al. 1990), aunque se incluye también a $C$. gracilior Phipps perteneciente a la serie Crus-galli (Loud.) Rehder.

Núñez-Colín et al. (2008) demostraron que genotipos originarios de Chiapas, que fueron identificados principalmente como C. stipulosa (Kunth) Steud. y $C$. nelsoni Eggl. usando las claves de Eggleston (1909), fueron morfológicamente diferentes a los genotipos del centro de México, que fueron identificados principalmente como C. mexicana DC y C. gracilior Phipps mediante las claves de Phipps (1997).

Recientemente, usando marcadores moleculares se trató de clarificar la complicada taxonomía del género Crataegus (Lo et al. 2007), pero en su estudio incluyeron muy pocas especies mexicanas. En este sentido, el ejemplar de C. mexicana DC utilizado en el estudio de Lo et al. (2007) fue obtenido de un genotipo propagado en Estados Unidos que puede no ser representativo de los genotipos de esta especie mexicana.

Por otro lado, los beneficios económicos actuales obtenidos de la mejora de la producción, calidad de los cultivos y la reducción del riesgo de la pérdida de las cosechas es muy importante; en este sentido, los silvestres relativos, como ancestros de los cultivos modernos, proveen genes útiles a los cultivos de importancia mundial en programas de mejoramiento genético (Zagaja 1988). En el caso específico del tejocote (Crataegus spp.) es un cultivo sin mejoramiento genético formal (Núñez-Colín et al. 2009); sin embargo, ha venido adquiriendo una alta relevancia comercial entre la población latina de los Estados Unidos (Karp 2010) por lo que siguiendo un mejoramiento genético formal pueden mejorarse la calidad nutrimental del fruto y hacerlo más atractivo y competitivo no sólo en Estados Unidos sino en México y Centroamérica donde también es cultivado y consumido (Núñez-Colín 2009, Núñez-Colín et al. 2008)

La presente investigación tuvo como objetivo determinar las relaciones genéticas entre especies de Crataegus del centro y sur de México y para verificar el postulado de que el complejo C. mexicana sensu lato es abundante en el centro y sur de México.

\section{MATERIALES Y MÉTODOS}

\section{Localización del ensayo}

Se trabajó en el laboratorio de marcadores moleculares del Departamento de Fitotecnia de la Universidad Autónoma Chapingo entre enero de 2006 y octubre de 2008.

\section{Material vegetal}

Se usó el ADN de 21 accesiones del banco de germoplasma de tejocote (Crataegus spp.) de la Universidad Autónoma Chapingo y que fueron identificadas como seis diferentes especies (Cuadro 1). Una de ellas fue identificada como $C$. pinnatifida Bunge (de origen Chino), la cual fue donada por el Dr. Leszek S. Jankiewicz del Research Institute of Pomology, Skiemiewioe, Polonia. Además se incluyeron accesiones mexicanas de C. mexicana DC (4), C. gracilior Phipps (4), C. stipulosa (Kunth) Steud. (6), C. nelsoni Eggl. (3) y tres accesiones que no pudieron ser identificadas (dos de Chiapas y una de Puebla y que basados en los comentarios del Dr. J. B. Phipps ${ }^{5}$ pudieran ser nuevas especies) y también se incluyó ADN de manzana 'ro-

5 Phipps, JB. 2009. Identificación de Ejemplares de Herbario de Crataegus mexicanos. London, Canadá. University of West Ontario. Comunicación personal. 
Cuadro 1. Datos de pasaporte de accesiones de Crataegus del Banco de germoplasma de Tejocote (Crataegus spp.) de la Universidad Autónoma Chapingo colectados en el 2007 y la manzana 'royal gala' (Malus x domestica Borkh.) usada como control positivo. México. 2008.

\begin{tabular}{|c|c|c|c|c|}
\hline Número de accesión & Código & Lugar de recolección & Identidad taxonómica & $\begin{array}{c}\text { Colector y año de la } \\
\text { colecta original }\end{array}$ \\
\hline 5 & RNU05 & Rancho Nuevo, Chiapas & C. stipulosa & Borys, 1982 \\
\hline 11 & HUE13 & Huejotzingo, Puebla & C. mexicana & Nieto, 1989 \\
\hline 17 & RNU07 & Rancho Nuevo, Chiapas & C. stipulosa & Borys, 1982 \\
\hline 25 & CALP6 & Calpan, Puebla & C. sp. * & Nieto y Borys, 1983 \\
\hline 26 & CALP3 & Calpan, Puebla & C. gracilior & Nieto y Borys, 1983 \\
\hline 34 & SNTP2 & San Nicolás Tlamincas, Mexico & C. gracilior & Nieto y Borys, 1982 \\
\hline 36 & SPI03 & San Pablo Ixayoc, Mexico & C. mexicana & Nieto y Borys, 1982 \\
\hline 54 & HUE05 & Huejotzingo, Puebla & C. mexicana & Nieto y Borys, 1983 \\
\hline 55 & HUE06 & Huejotzingo, Puebla & C. gracilior & Nieto y Borys, 1983 \\
\hline 59 & CAN02 & Candelaria, Chiapas & C. stipulosa & Nieto y Barrientos, 1989 \\
\hline 70 & CAN06 & Candelaria, Chiapas & C. nelsoni & Nieto y Barrientos, 1989 \\
\hline 71 & SJY01 & San José Yashitinin, Chiapas & C. sp. * & Nieto y Barrientos, 1989 \\
\hline 72 & SJY02 & San José Yashitinin, Chiapas & C. sp. * & Nieto y Barrientos, 1989 \\
\hline 81 & $\mathrm{SCC} 07$ & San Cristóbal de las Casas, Chiapas & C. nelsoni & Nieto y Barrientos, 1989 \\
\hline 82 & SCC08 & San Cristóbal de las Casas, Chiapas & C. nelsoni & Nieto y Barrientos, 1989 \\
\hline 83 & SCC09 & San Cristóbal de las Casas, Chiapas & C. stipulosa & Nieto y Barrientos, 1989 \\
\hline 86 & HUE10 & Huejotzingo, Puebla & C. mexicana & Nieto y Barrientos, 1988 \\
\hline 88 & $\mathrm{SCC} 12$ & San Cristóbal de las Casas, Chiapas & C. stipulosa & Nieto y Barrientos, 1989 \\
\hline 89 & SCC13 & San Cristóbal de las Casas, Chiapas & C. stipulosa & Nieto y Barrientos, 1989 \\
\hline 91 & XАM02 & Xamimilulco, Puebla & C. gracilior & Nieto y Barrientos, 1988 \\
\hline $\mathrm{CP}$ & $\mathrm{CP}$ & Polonia (Donación) & C. pinnatifida & Jankiewicz, 2000 \\
\hline MZ & & Toluca, México & M. x domestica & Núñez-Colín, 2007 \\
\hline
\end{tabular}

* Estas accesiones no pudieron ser identificadas mediante las claves de Phipps (1997) ni las de Eggleston (1909).

yal gala' (Malus x domestica Borkh.) como control positivo.

\section{Procedimientos de extracción de ADN, PCR y Se- cuenciación}

Se extrajo ADN genómico total de hojas jóvenes deshidratadas con sílica gel con base en el protocolo de CTAB propuesto por Weising et al. (2005). Se usaron los iniciadores ITS4 e ITS5 para amplificar la región ribosómica nuclear, que comprende el ITS1, el gen 5.8S rDNA y el ITS 2 (White et al. 1990); la decisión sobre utilizar ITS y no otros genes conservados fue debido a que se ha demostrado que esta secuencia nuclear es una de las más útiles para hacer filogenia en la subtribu Pyrinae (Campbell et al. 2007) así como del género Crataegus (Lo et al. 2007). Además, se utilizó la mezcla de reacción de PCR y las condiciones de termociclaje propuestas por Lo et al. (2007).

Los productos de PCR fueron visualizados en geles de agarosa (1\%) y purificados con filtros de sílice y diferentes soluciones comerciales de alcoholes y sales. Después, estos productos fueron secuenciados en Seúl, Corea por la empresa Macrogen, y las secuencias fueron leídas y analizadas en ambos sentidos (5' y 3') con el programa BioEdit version 7.0.5.3 (Hall 1999). 


\section{Análisis estadísticos}

Se realizaron para todas las secuencias un alineamiento múltiple usando el modelo Clustal X. Una vez alineadas se obtuvieron las frecuencias de nucleótidos para cada accesión. Se obtuvo una clasificación filogenética utilizando el método Neighbor-Joining (Saitou y Nei 1987); el filograma obtenido fue validado utilizando el método Bootstrap con 1000 remuestros (Efron 1979).

Se obtuvo la prueba de homogeneidad de los patrones de sustitución entre secuencias y el índice de disparidad por medio de la distancia de composición. La prueba de homogeneidad de los patrones de sustitución entre las secuencias es un índice de disparidad (una distancia genética), que es evaluada por medio de una prueba de hipótesis para conocer si las secuencias evaluadas tienen un mismo patrón de sustitución. Si la hipótesis no es rechazada, entonces esas dos secuencias tienen el mismo patrón aunque puede existir un cierto grado de diferencias o sesgo en la composición de bases (Tamura et al. 2007a, Tamura et al. 2007b). La distancia de composición es una medida para conocer las diferencias en la composición de nucleótidos entre dos diferentes secuencias (Tamura et al. 2007a). Todos los análisis fueron realizados usando el programa Mega 4 (Tamura et al. 2007a).

\section{RESULTADOS Y DISCUSIÓN}

Los porcentajes de los diferentes nucleótidos fueron similares en todas las accesiones, especialmente en Guanina (G) y Adenina (A), pero existió un cambio en la frecuencia de Timina (T) y Citosina (C) entre los Crataegus mexicanos, el Crataegus chino y aún más significativamente fue esta variación con la manzana. Sin embargo, todas las accesiones mexicanas presentaron el mismo patrón (Cuadro 2).

C. pinnatifida Bunge presentó una secuencia con dos bases menos que los Crataegus mexicanos y la manzana presentó 28 bases menos que las accesiones mexicanas de Crataegus (Cuadro 2).

En el filograma se observa que todos los Crataegus mexicanos estuvieron estrechamente relacionados, este grupo se unió a $C$. pinnatífida y la manzana mostró una mayor distancia al grupo de los Crataegus (Figura 1). Sin embargo, las accesiones mexicanas de
Cuadro 2. Frecuencias de nucleótidos de las secuencias de la región ribosómica nuclear de 20 accesiones mexicanas de Crataegus, una accesión de $C$. pinnatífida Bunge y una accesión de manzana (Malus x domestica Borkh.) de DNA extraido en el laboratorio del departamento de Fitotecnia de la Universidad Autónoma Chapingo, México, de enero de 2007 a septiembre del 2008.

\begin{tabular}{cccccc}
\hline $\begin{array}{c}\text { Número de } \\
\text { accesión }\end{array}$ & $\begin{array}{c}\text { T } \\
(\boldsymbol{\%})\end{array}$ & $\begin{array}{c}\mathbf{C} \\
(\boldsymbol{\%})\end{array}$ & $\begin{array}{c}\mathbf{A} \\
(\mathbf{\%})\end{array}$ & $\begin{array}{c}\mathbf{G} \\
(\mathbf{\%})\end{array}$ & $\begin{array}{c}\text { Nucleóti- } \\
\text { dos totales }\end{array}$ \\
\hline 5 & 16,1 & 34,2 & 18,1 & 31,6 & 652 \\
11 & 16,1 & 34,2 & 18,1 & 31,6 & 652 \\
54 & 16,1 & 34,2 & 18,1 & 31,6 & 652 \\
86 & 16,1 & 34,4 & 18,1 & 31,4 & 652 \\
17 & 16,1 & 34,4 & 18,1 & 31,4 & 652 \\
89 & 16 & 34,5 & 18,1 & 31,4 & 652 \\
88 & 16,1 & 34,4 & 18,1 & 31,4 & 652 \\
34 & 16 & 34,5 & 18,1 & 31,4 & 652 \\
59 & 16 & 34,5 & 18,1 & 31,4 & 652 \\
72 & 16 & 34,4 & 18,1 & 31,5 & 652 \\
71 & 16 & 34,4 & 18,1 & 31,5 & 652 \\
36 & 16,1 & 34,2 & 18,1 & 31,6 & 652 \\
55 & 16,1 & 34,2 & 18,1 & 31,6 & 652 \\
25 & 16,1 & 34,4 & 18,1 & 31,4 & 652 \\
70 & 16 & 34,5 & 18,1 & 31,4 & 652 \\
81 & 16 & 34,5 & 18,1 & 31,4 & 652 \\
26 & 16 & 34,5 & 18,2 & 31,3 & 652 \\
82 & 16,3 & 34,2 & 17,9 & 31,6 & 652 \\
91 & 16,1 & 34,5 & 18,1 & 31,3 & 652 \\
83 & 16,3 & 34,2 & 17,9 & 31,6 & 652 \\
CP & $\mathbf{1 7 , 1}$ & $\mathbf{3 3 , 7}$ & 17,8 & 31,4 & $\mathbf{6 5 0}$ \\
MZ & $\mathbf{1 9 , 5}$ & $\mathbf{3 1 , 3}$ & 17,6 & 31,6 & $\mathbf{6 2 4}$ \\
\hline Promedio & 16,3 & 34,2 & 18,1 & 31,5 & 650,6 \\
\hline & & & & &
\end{tabular}

Crataegus no tuvieron una estructura taxonómica entre las especies identificadas debido a que solamente se encontraron diferencias mínimas entre sus secuencias.

La manzana presentó un patrón de sustitución estadísticamente diferente con todas las accesiones de Crataegus (Cuadro 3) en la prueba de homogeneidad de los patrones de sustitución. Por otra parte, todos los patrones de sustitución de las accesiones de Crataegus 


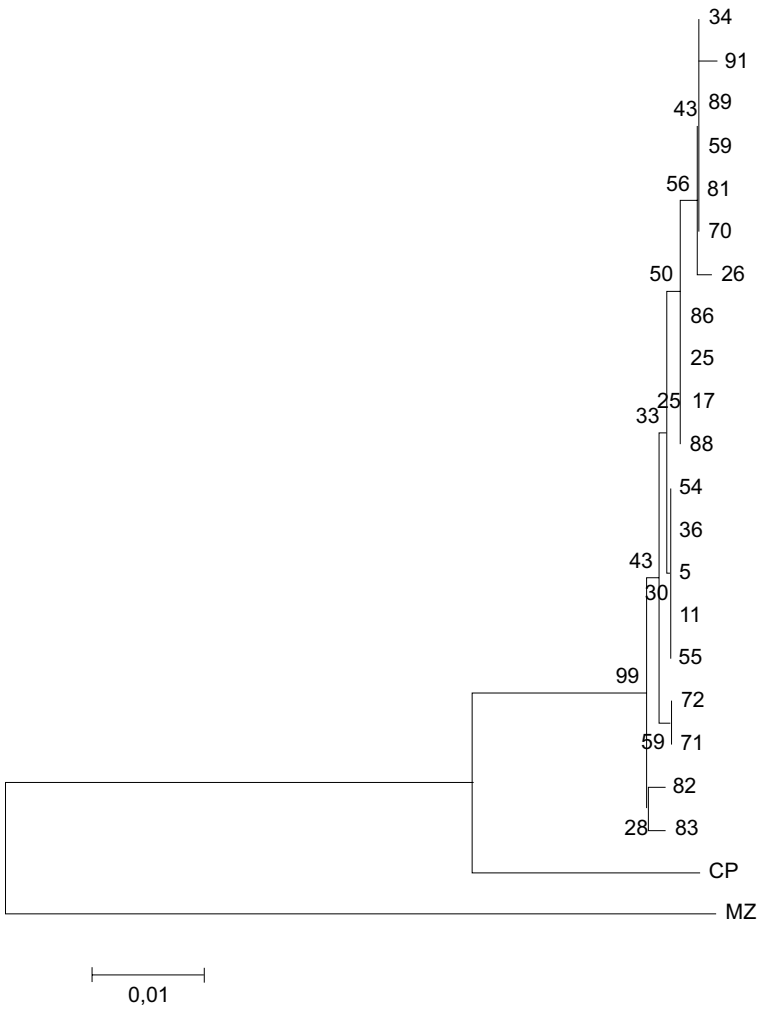

Figura 1. Filograma de 20 accesiones mexicanas de $\mathrm{Cra}$ taegus, una accesión de $C$. pinnatífida Bunge y una accesión de manzana 'royal gala' (Malus $\mathrm{x}$ domestica Borkh.) mediante las secuencias de la región ribosómica nuclear con base en el método Neighbor-Joining y validado mediante el método Bootstrap con 1000 remuestreos de DNA extraído en el laboratorio del departamento de Fitotecnia de la Universidad Autónoma Chapingo, México de enero de 2007 a septiembre del 2008.

en la región ribosómica nuclear fueron similares, aunque $C$. pinnatífida presentó un alto valor en el índice de disparidad al compararlo con la mayoría de los Crataegus mexicanos, con excepción de las accesiones 82 y 83 identificadas como C. nelsoni Eggl. y C. stipulosa (Kunth) Steud., respectivamente. Ambas accesiones originarias de San Cristóbal de la Casas, Chiapas tuvieron un patrón de sustitución idéntico entre ellas (Cuadro 3).

Todas las accesiones mexicanas mostraron valores bajos en el índice de disparidad entre ellos $(0,0000$ y 0,0048), las mexicanas de Crataegus tuvieron patrones de sustitución idénticos en la región ribosómica nuclear o pudieran tener variaciones mínimas entre sus patrones (Cuadro 3).

La manzana tuvo los más altos valores en la distancia de composición en comparación con todos los Crataegus; lo que significa que la manzana presentó la mayor diferencia en la secuencia de la región ribosómica nuclear entre todas las accesiones estudiadas (Cuadro 4).

C. pinnatifida mostró altos valores en la distancia de composición con todas las accesiones mexicanas debido a que el máximo valor ellas fue de 0,0128 , obtenido entre las 82 y 83 con la accesión 26, más bajo que cualquier valor entre $C$. pinnatifida con cualquiera de las mexicanas (Cuadro 4).

Dentro de las accesiones mexicanas, las identificadas como $C$. stipulosa presentaron valores de distancia de cero como mínimo, con accesiones identificadas como otras especies. Esto da como resultado que se tengan secuencias idénticas entre algunas de $C$. stipulosa y de otras especies (Cuadro 5).

C. gracilior fue la única especie que no mostró secuencias idénticas entre accesiones identificadas como esta; sin embargo, algunas accesiones de $C$. gracilior presentaron secuencias idénticas con accesiones de $C$. mexicana, C. stipulosa y C. nelsoni (Cuadro 5).

C. mexicana mostró la distancia promedio más baja entre sus accesiones de todas las especies en estudio, aunque también presentó un alto coeficiente de variación, esto es porque sólo una accesión tuvo una diferente secuencia en la región ribosómica nuclear (Cuadro 5).

Accesiones de C. nelsoni presentaron secuencias idénticas con los de otras especies excepto con las accesiones no identificadas de Crataegus (Cuadro 5). Además, presentó el más alto valor promedio entre sus accesiones en todas las especies mexicanas.

Las accesiones de especies no identificadas $(C$. sp.) mostraron la misma secuencia entre sus accesiones de Chiapas y tuvieron unos pocos cambios con la de Puebla, pero sólo mostraron diferencias con todas las otras especies excepto con C. stipulosa. Además, presentaron el segundo más bajo valor promedio entre sus accesiones después de $C$. mexicana.

Se encontró una muy alta similaridad en las secuencias de la región ribosómica nuclear entre los 


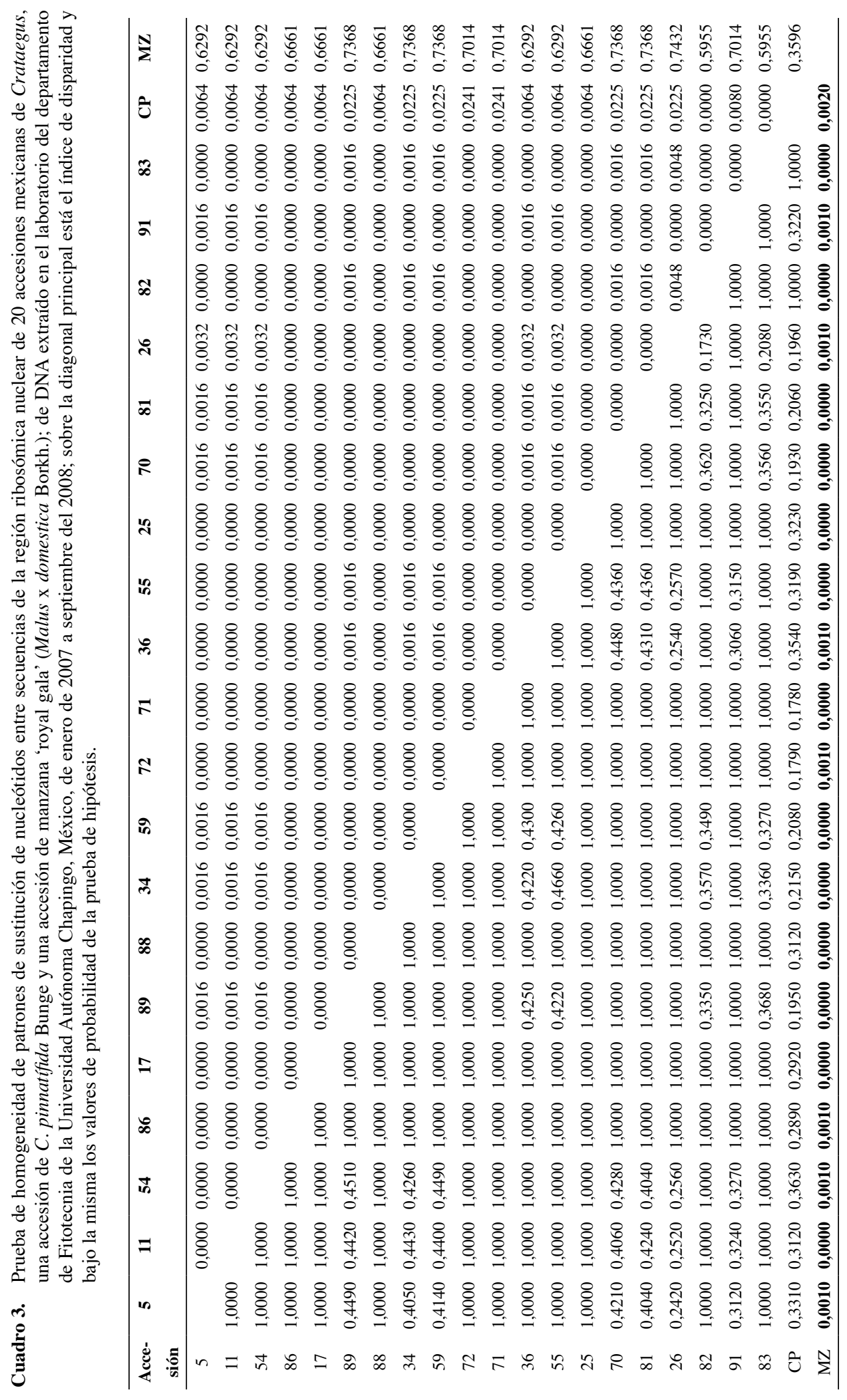




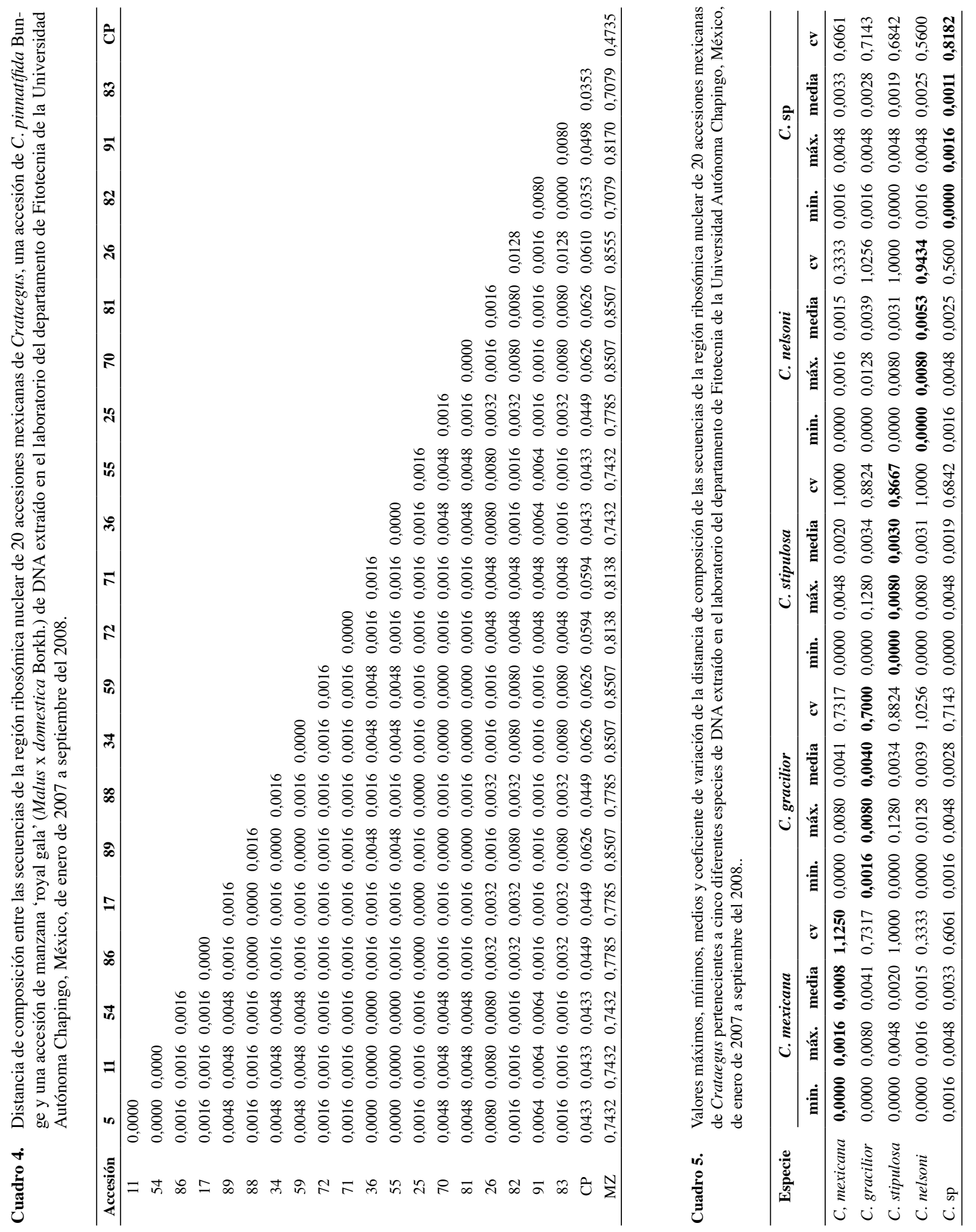


Crataegus mexicanos aquí estudiados, lo que significa que se encuentran genéticamente relacionados; sin embargo, Núñez-Colín et al. (2008) demostraron que accesiones de Chiapas (sur de México) son morfológicamente diferentes en comparación con las del centro de México; por lo que pueden considerarse especies relacionadas pero diferentes. Estos hallazgos corroboran el postulado de Phipps (1997) sobre que los materiales del centro y sur de México pertenecen a un complejo taxonómico alrededor de C. mexicana sensu lato.

Por otro lado, Phipps et al. (1990) clasificaron, a C. nelsoni y C. stipulosa dentro de la serie Mexicanae (Loud.) Rehder, pero es necesario revisar la clasificación taxonómica para los Crataegus del sur de México y considerar que algunas de las accesiones de Chiapas puedan ser reclasificadas como nuevas especies debido a que se pueden tener errores de clasificación por utilizar las claves taxonómicas de Eggleston (1909). Es por esto que existe la duda sobre si los especímenes de Crataegus de Chiapas realmente pertenecen a la serie Maexicanae o que puedan pertenecer a series relacionadas como la Serie Crus-galli (Loud.) Rehder.

En esta investigación no es claro si $C$. gracilior pertenece a la serie Crus-galli debido a que estas accesiones mostraron similaridad en la secuencia de la región ribosómica nuclear con otras accesiones que se menciona, por la especie que se identificó, que pertenecen a la Serie Mexicanae (Phipps et al. 1990). Phipps (1997) demostró usando morfología que $C$. gracilior pertenece a la serie Crus-galli pero no se encontraron las diferencias esperadas en esta investigación.

Debido a que las accesiones mexicanas de $\mathrm{Cra}$ taegus se distribuyeron de manera aleatoria dentro del filograma no pudo observarse grupos por cada una de las especies; además, dichas accesiones presentaron el mismo patrón de sustitución de nucleótidos y valores bajos de la distancia de composición. Esto puede ser interpretado como que todas las accesiones de Crataegus del centro y sur de México están estrechamente relacionadas y pudieron ser originadas por un ancestro en común reciente (Saitou y Nei 1987, Kumar y Gadagkar 2001, Tamura et al. 2007b), o bien puede tratarse de variantes de una misma especie, pero para corroborar esta afirmación deben probarse con otras secuencias de genes filogenéticos como las regiones intragénicas de $\mathrm{ADN}$ de cloroplasto, el segundo intron del gen LEAFY, etc. (Lo et al. 2007).
Estos resultados no sólo son importantes desde el punto de vista taxonómico, sino que también pueden ser utilizados en gestión de los recursos genéticos de este género. Por ejemplo, si los datos de Talent y Dickinson (2005) pudieran ser generalizados sobre que $C$. mexicana y $C$. stipulosa son diploides y poder probar el nivel de ploidía de $C$. nelsoni; estas especies de Chiapas pueden ser una fuente de genes para programas de mejoramiento genético de $C$. mexicana que es la especie más cultivada y usada en México, además de que tiene el mejor potencial agronómico (Zagaja 1988, Büttner 2001, Núñez-Colín et al. 2009, Karp 2010). Algunos especímenes de C. stipulosa y C. nelsoni del Banco de Germoplasma de Tejocote de la Universidad Autónoma Chapingo presentan características deseables en cuanto a color de pulpa y de cáscara, así como en compuestos fenólicos y otras sustancias que serían deseables incorporar a los tejocotes cultivados (Núñez-Colín et al. 2007, Núñez-Colín 2009) y que en esta investigación dichas especies mostraron una alta similitud genética con la cultivada.

Puede concluirse que la variación en las secuencias de la región ribosómica nuclear fue baja en todas las accesiones del germoplasma mexicano de $\mathrm{Cra}$ taegus. Además, en el filograma sólo se muestra la separación de las especies utilizadas como controles positivos por lo que no se observaron grupos de especies de manera clara.

Además, todas las accesiones mexicanas de Crataegus tienen el mismo patrón de sustitución de nucleótidos y muy bajos valores de la distancia de composición de nucleótidos; por lo tanto, las especies de Crataegus mexicanas tienen una alta relación genética entre ellas, pero falta evidencia sobre si se trata de variantes de una misma especie taxonómica, po lo que se podría considerar que todos los $\mathrm{Cra}$ taegus del centro y sur de México son un complejo taxonómico alrededor de C. mexicana sensu lato, aunque hay que secuenciar otros genes filogenéticos para corroborarla.

C. nelsoni y C. stipulosa pueden ser estimados como una fuente de genes para $C$. mexicana, que es la especie que presenta las mejores características agronómicas, porque ambas especies de Chiapas son las más estrechamente relacionadas con esta especie cultivada. 


\section{AGRADECIMIENTOS}

Este estudio fue financiado en parte por el Consejo Nacional de Ciencia y Tecnología de México (CONACYT) por medio de la beca número 169581 y por el Servicio Nacional de Identificación y Certificación de Semillas (SNICS) de la Secretaria de Agricultura, Ganadería, Desarrollo Rural, Pesca y Alimentación (SAGARPA) por medio del proyecto número $53 \mathrm{del}$ Sistema Nacional de Recursos Fitogenéticos-Red Frutales del último autor.

\section{LITERATURA CITADA}

Büttner, R. 2001. Rosaceae. In P. Hanelt; Institute of Plant Genetics and Crop Plant research eds. Mansfeld's Encyclopedia of Agricultural and Horticultural Crops: except ornamentals. Springer, Berlin-Heidelberg-New York. p. 417-532.

Campbell, CS; Evans, RC; Morgan, DR; Dickinson, TA; Arsenault, MP. 2007. Phylogeny of subtribe Pyrinae (formely the Maloideae, Rosaceae): Limited resolution of a complex evolutionary history. Plant Systematics and Evolution 266:119-145.

Efron, B. 1979. Bootstrap methods: another look at the jackknife. The Annals of Statistics 7:1-26.

Eggleston, WW. 1909. The Crataegi of Mexico and Central America. Bulletin of the Torrey Botanical Club 36: 501-514.

Hall, TA. 1999. BioEdit: a user-friendly biological sequence alignment editor and analysis program for Windows 95/98/NT. Nucleic Acids Symposium Series 41:95-98.

Karp, D. 2010. Tejocote: No longer forbidden. Fruit Gardener 42(6):10-13.

Kumar, S; Gadagkar, SR. 2001. Disparity index: A simple statistic to measure and test the homogeneity of substitution patterns between molecular sequences. Genetics 158:1321-1327.

Lo, EYY; Stefanovic, S; Dickinson, TA. 2007. Molecular reappraisal of relationships between Crataegus and Mespilus (Rosaceae, Pyreae) - Two genera or one? Systematic Botany 32(3):596-616.

Núñez-Colín, CA. 2008. Variabilidad inter e intra específica del germoplasma de tejocote (Crataegus spp.) del centro y sur de México. Ph D. Thesis. Instituto de Horticultura, Universidad Autónoma Chapingo, Chapingo, Mexico. 120 p.
Núñez-Colín, CA. 2009. The tejocote (Crataegus spp.): A Mexican plant genetic resource that is wasted, a review. Acta Horticulturae 806:339-346.

Núñez-Colín, CA; García-Mateos, R; Nieto-Ángel, R; SotoHernández, M. 2007. Caracterización de genotipos de Crataegus en relación al contenido de compuestos fenólicos. Proceedings of the Interamerican Society for Tropical Horticulture 51:124-127.

Núñez-Colín, CA; Nieto-Ángel, R; Barrientos-Priego, AF; Sahagún-Castellanos, J; Segura, S; González-Andrés, F. 2008. Variability of three regional sources of germplasm of tejocote (Crataegus spp.) from central and southern Mexico. Genetic Resources and Crop Evolution 55(8):1159-1165.

Núñez-Colín, CA; Sahagún-Castellanos, J; González-Andrés, F; Barrientos-Priego, AF; Segura, S; Nieto-Ángel, R. 2009. Identification of morphometric traits for screening of tejocote (Crataegus spp.) germplasm for better yield potential. Fruits 64:35-44.

Phipps, JB. 1997. Monograph of Northern Mexican Crataegus (Rosaceae subfam. Maloideae). SIDA Botanical Miscellany 15:1-94.

Phipps, JB; O’Kennon, RJ; Lance, RW. 2003. Hawthorns and Medlars. Timber Press, Portland, USA. 139 p.

Phipps, JB; Robertson, KR; Smith, PG; Rohrer, JR. 1990. A checklist of the subfamily Maloideae (Rosaceae). Canadian Journal of Botany 68:2209-2269.

Saitou, N; Nei, M. 1987. The Neighbor-joining method: a new method for reconstructing phylogenetic trees. Molecular Biology and Evolution 4(4):406-425.

Talent, N; Dickinson, TA. 2005. Polyploidy in Crataegus and Mespilus (Rosaceae, Maloideae): evolutionary inference from flow cytometry of nuclear DNA amounts. Canadian Journal of Botany 83:1268-1304.

Tamura, K; Dudley, J; Nei, M; Kumar, S. 2007a. MEGA. Molecular Evolutionary Genetics Analysis Version 4. User's Guide. Center of Evolutionary Functional Genomics, Biodesign Institute, Arizona State University. Tempe, USA. 229 p.

Tamura, K; Dudley, J; Nei, M; Kumar, S. 2007b. MEGA4: Molecular Evolutionary Genetics Analysis (MEGA) software version 4.0. Molecular Biology and Evolution 24(8):1596-1599

Weising, K; Nybon, H; Wolf, K; Kahl, G. 2005. DNA fingerprinting in plants. Principles, methods and applications. 2 ed. CRC Press, Boca Raton, USA. 472 p.

White, TJ; Bruns, T; Lee, S; Taylor, J. 1990. Amplification and direct sequencing of fungal ribosomal genes for 
phylogenies. In Innis, M; Gelfand, D; Sninsky, J; White T. eds. PCR protocols: A guide to methods and applications. Academic Press, San Diego, USA. p. 315-322.
Zagaja, SW. 1988. Exploración de recursos genéticos. In Moore, JN; Janick, J. eds. Métodos genotécnicos en frutales, AGT Editor, Mexico City, Mexico. p. 3-12. 